\title{
Randomised controlled trial of aminophylline for severe acute asthma
}

\author{
Michael Yung, Mike South
}

\begin{abstract}
Objectives-To determine whether children with severe acute asthma treated with large doses of inhaled salbutamol, inhaled ipratropium, and intravenous steroids are conferred any further benefits by the addition of aminophylline given intravenously.

Study design-Randomised, double blind, placebo controlled trial of 163 children admitted to hospital with asthma who were unresponsive to nebulised salbutamol.

Results-The placebo and treatment groups of children were similar at baseline. The 48 children in the aminophylline group had a greater improvement in spirometry at six hours and a higher oxygen saturation in the first 30 hours. Five subjects in the placebo group were intubated and ventilated after enrolment compared with none in the aminophylline group.

Conclusions-Aminophylline continues to have a place in the management of severe acute asthma in children unresponsive to initial treatment.

(Arch Dis Child 1998;79:405-410)
\end{abstract}

Keywords: asthma; aminophylline; randomised controlled trial

Most children admitted to hospital with acute asthma will improve with nebulised $\beta_{2}$ agonists, such as salbutamol, and systemic corticosteroids, ${ }^{1}$ with or without nebulised ipratropium. ${ }^{2}$ A few with severe acute asthma will not, however, respond to these drugs and require additional treatment to avoid respiratory muscle fatigue and respiratory failure.

Despite conflicting evidence about its effectiveness, aminophylline is still recommended by the National Heart, Lung and Blood Institute of the USA and the British Thoracic Society for the treatment of children with severe acute asthma unresponsive to frequent $\beta_{2}$ agonists and corticosteroids. ${ }^{34}$

Controlled trials of aminophylline in adults

Intensive Care Unit, Royal Children's Hospital, Melbourne, Victoria 3052,

Australia

M Yung

M South

Correspondence to: Dr South.

email: south@cryptic.rch. unimelb.edu.au

Accepted 11 May 1998 have had conflicting results. Early studies used currently outmoded sympathomimetic drugs, ${ }^{5-7}$ so that their relevance to current clinical practice is questionable. Patient selection and methodological problems make more recent trials showing no benefit from aminophylline difficult to interpret. Some studies have excluded patients with severe asthma, ${ }^{8}$ whereas others have not selected patients unresponsive to nebulised sympathomimetic drugs. $^{9-12}$ Methodological problems such as the inclusion of patients already taking theophylline by mouth, ${ }^{811-13}$ a lack of blinding, ${ }^{13}$ and low power $^{913}$ are also problem areas. Two studies in adults have found a benefit. One used infrequent doses of salbutamol and excluded severely ill patients, ${ }^{14}$ and the other showed a reduction in the rate of admission to hospital. ${ }^{15}$

Five controlled trials, the largest of which studied 42 subjects, ${ }^{16}$ have been performed in children. One showed that aminophylline improved the forced expiratory volume in one second $\left(\mathrm{FEV}_{1}\right)$, but used currently outmoded sympathomimetic drugs. ${ }^{17}$ Four showed no benefit, but all excluded severely ill patients. ${ }^{161819}$ Methodological problems included low power ${ }^{19}$ and withdrawals for a lack of response. ${ }^{20}$

We performed a randomised, double blind, placebo controlled trial to answer the question: Do children with severe acute asthma unresponsive to frequent doses of $\beta$ agonists, ipratropium, and steroids benefit from the addition of aminophylline given intravenously? We aimed to study the most severely ill children with severe acute asthma, including those too sick to perform pulmonary function tests, those admitted to the intensive care unit, and those requiring mechanical ventilation.

\section{Methods}

Eligible subjects were children (aged 1-19 years) with severe acute asthma who were unresponsive to three nebulised doses of $5 \mathrm{mg}$ salbutamol. Subjects had to have an asthma severity score (ASS; see later) of $>6$, spirometry (where possible) of $<50 \%$ predicted, or be obviously very sick and being admitted to the intensive care unit. Unresponsive to nebulised salbutamol meant no improvement in an ASS of $>1$, or spirometry of $>15 \%$. Exclusion criteria were: pregnancy, other chronic respiratory disease (for example, bronchopulmonary dysplasia or cystic fibrosis), significant disease of other organ systems, a known adverse reaction to theophylline, previous enrolment, and administration of theophylline (by mouth or intravenously) in the previous 24 hours.

The parents of participating children gave written informed consent. The study was approved by the institutional human ethics committee.

All subjects were given standard care for our institution. Frequent nebulised salbutamol, 5 $\mathrm{mg} /$ dose in a volume of $4 \mathrm{ml}$, was given through a jet nebuliser driven by $8-10$ litres/min of oxygen. The dosing frequency of nebulised salbutamol and the use of salbutamol given intravenously were determined by the medical 
staff carrying out the treatment and were not dictated by the study protocol. Also given were nebulised ipratropium bromide $250 \mu \mathrm{g}$ every four to six hours and intravenous methylprednisolone $1 \mathrm{mg} / \mathrm{kg}$ every six hours, followed by oral prednisolone $1 \mathrm{mg} / \mathrm{kg}$ twice daily during convalescence.

Subjects were randomised to receive either aminophylline or a sterile water placebo (both clear, colourless, odourless fluids) from glass ampoules which were identical in appearance. Aminophylline infusions were given as a loading dose of $10 \mathrm{mg} / \mathrm{kg}$ infused over one hour, followed by a continuous infusion of 1.1 or $0.7 \mathrm{mg} / \mathrm{kg} /$ hour for subjects younger than 10 years and 10 years of age or older, respectively. Placebo infusions were given in the same fluid at the same volumes and rates. The duration of the infusion was determined by the medical staff giving the treatment and not by the investigators.

Sequentially numbered boxes were randomly assigned to contain either aminophylline or placebo using a computer generated code with randomly permuted blocks of different sizes (two, four, and six subjects) such that the balance between the treatment arms was maintained every 12 subjects. Subjects were stratified by age as older and younger than 6 years.

Theophylline concentrations were measured within one hour of the completion of the loading dose, and again 12-18 hours later if the subject was still receiving the infusion. The results were conveyed to the second investigator (MS), who issued instructions to the medical staff carrying out the treatment, who then adjusted the infusions according to a protocol determined at the beginning of the study aimed at achieving concentrations in the high therapeutic range $(80-110 \mathrm{mmol} / \mathrm{l})$. Instructions consistent with the protocol used for aminophylline infusions were issued for patients receiving the placebo.

The principal investigator, the medical and nursing staff carrying out the treatment, and the subject and his or her family were blind to the treatment group. Blinding was maintained throughout the period of hospital admission and to the end of the study. Only the statistician, the pharmacist, and the second investigator (MS) were aware of the assignment, and none was directly involved in the care of the patients.

At enrolment, the age, sex, weight, previous asthma history, ${ }^{1}$ drug treatments, comorbidity, pulmonary function test data, and percutaneous oxygen saturation $\left(\mathrm{SaO}_{2}\right)$ were recorded.

The first principal outcome measure was the length of stay in hospital. The second principal outcome measure was spirometry using a portable spirometer, which was calibrated before each use. Values of $\mathrm{FEV}_{1}$, forced vital capacity, maximum mid-expiratory flow, and peak flow were recorded and expressed as percentages of that predicted for the subject's age, height, sex, and race. ${ }^{21}$ Spirometry was performed at baseline, at six hours, 12-18 hours, 18-24 hours, and daily thereafter. All measurements were made in a blind manner by the principal investigator (MY).
Percutaneous oxygen saturation, after breathing air for 10 minutes, was measured every six hours via a finger probe with a pulse oximeter. The measurement was recorded when the signal was stable, without movement artefact, and when the oximeter gave an accurate pulse rate. If the $\mathrm{SaO}_{2}$ fell below $80 \%$ during the 10 minutes of air breathing, it was recorded as " $<80$ ", and supplemental oxygen was reinstated.

The ASS, ${ }^{22}$ the sum of scores for wheeze, accessory muscle use, and heart rate, was recorded by the nurse caring for the subject every six hours throughout the time the subject was receiving the study drug infusion and for 24 hours thereafter. The ASS was not recorded for the subjects receiving mechanical ventilation.

Heart rate, respiratory rate, the total duration and flow rate of supplemental oxygen, the number of doses, and the dose in milligrams of salbutamol given were all recorded.

Adverse effects, including nausea, vomiting, headaches, irritability, tremor, and seizures, were recorded every six hours by the nurse caring for the subject. Nursing staff were asked to enquire specifically about each symptom and to record it as present if it had occurred at any time in the previous six hour period. The development of adverse effects which were not present at enrolment were defined as "new" for the purpose of analysis. Headaches and nausea in the absence of vomiting could not be recorded if the child was too young or sick to answer.

For mechanically ventilated subjects, the duration of mechanical ventilation, and the area under the peak pressure-time curve were analysed.

Sample size calculations were performed using PC Size, ${ }^{23}$ based on length of stay and spirometry as the primary outcome measures. From the most recent figures available for our institution for patients with severe acute asthma, the mean length of stay was 2.3 days, with an SD of 1.0 days. A reduction in length of stay of 12 hours or more was considered the smallest clinically important difference which might be produced by aminophylline. To detect a 0.5 day reduction in length of stay with $90 \%$ power, and a value of 0.05 , we aimed to study 172 subjects, 86 in each group. We knew that only a proportion of the subjects would be able to perform spirometry, the others being too young or too sick. We aimed to study 22 in each group to detect a difference in $\mathrm{FEV}_{1}$ of $10 \%$ points at six hours, with $90 \%$ power and a value of 0.05 .

Results are expressed as means and SDs for normally distributed data and as medians and ranges for non-normal data. Treatment groups were compared by the unpaired Student's $t$ test for normally distributed data and the MannWhitney U test for non-normally distributed data. Logarithmic transformations of skewed data were performed to make the data normally distributed where possible. Spirometric data were analysed by the change from baseline in percentage predicted values at different time points, but the change from baseline at six hours was the principal spirometric outcome, specified in advance. Analysis of covariance 
Table 1 Baseline characteristics of both groups

\begin{tabular}{lll}
\hline & Aminophylline $(n=81)$ & Placebo $(n=82)$ \\
\hline Median (range) age (months) & $76.2(12.9-237.8)$ & $74.2(13.8-234.1)$ \\
Sex (male) & $43(53 \%)$ & $46(56 \%)$ \\
Pulmonary function tests & $(\mathrm{n}=27)$ & $(\mathrm{n}=21)$ \\
Mean (SD) FVC\% & $51.4(19.0)$ & $51.8(19.7)$ \\
Mean (SD) FEV $\%$ & $35.5(17.9)$ & $38.5(14.4)$ \\
Median (range) MMEF\% & $14.0(6.3-87.5)$ & $19.4(12.1-47.4)$ \\
Mean (SD) PEFR\% & $38.7(13.5)$ & $43.9(14.6)$ \\
Median (range) SaO & $88 \%(75-100 \%)$ & $89.5 \%(75-100 \%)$ \\
Median (range) asthma severity score & $8(4-9)$ & $8(4-9)$ \\
Mean (SD) heart rate & $166(23.3)$ & $168(22.0)$ \\
Median (range) respiratory rate & $42(14-84)$ & $40(12-91)$ \\
Past history & $26(32 \%)$ & $22(39 \%)$ \\
Episodic asthma & $52(64 \%)$ & $50(61 \%)$ \\
Persistent asthma & $24(30 \%)$ & $21(26 \%)$ \\
Regular $\beta_{2}$ agonists & $13(16 \%)$ & $10(12 \%)$ \\
Cromoglycate & $40(49 \%)$ & $33(40 \%)$ \\
Inhaled steroids & $2(2 \%)$ & $3(4 \%)$ \\
Oral steroids & &
\end{tabular}

FVC, forved vital capacity; $\mathrm{FEV}_{1}$, forced expiratory volume in one minute; MMEF, maximum mid-expiratory flow; PEFR, peak expiratory flow rate.

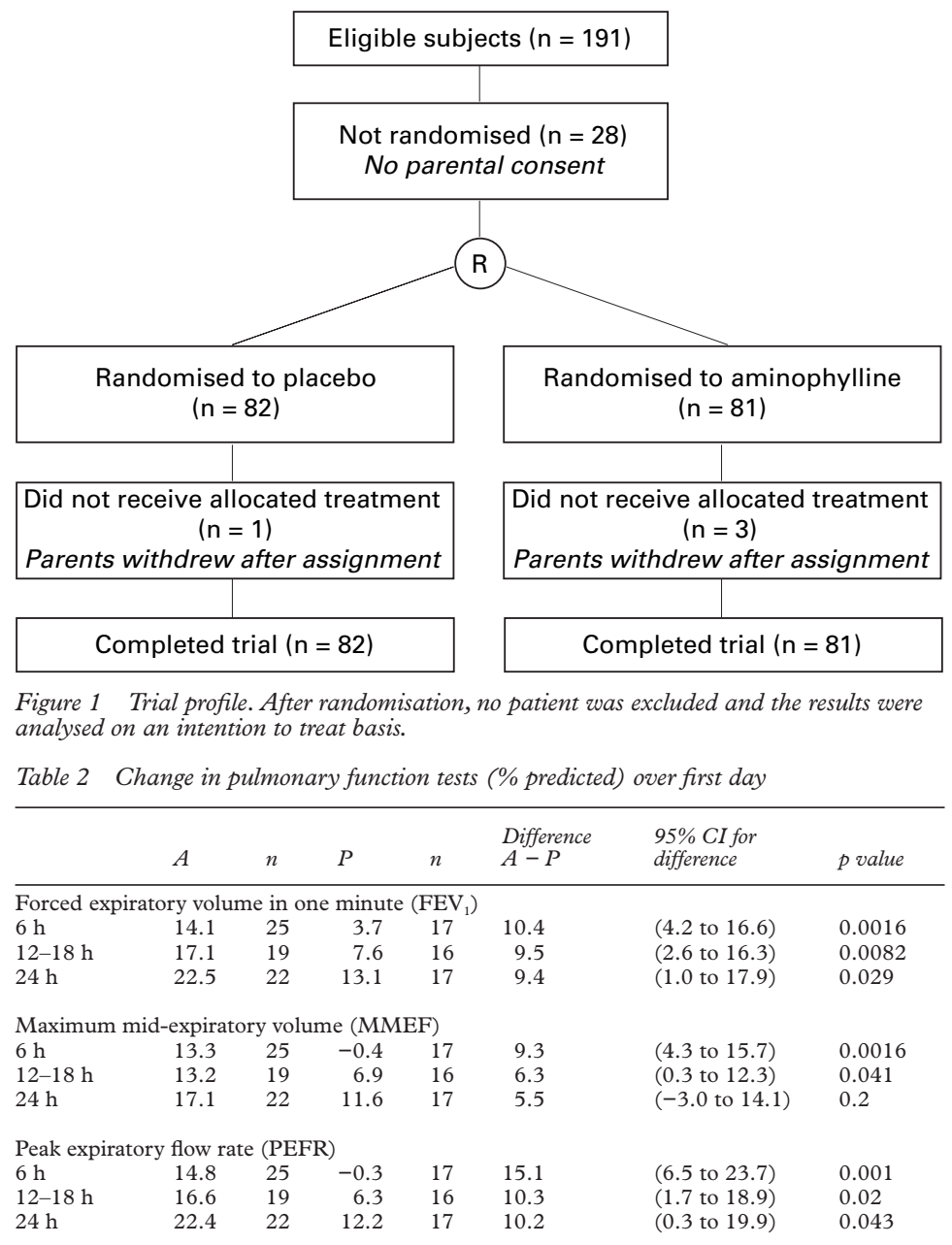

Group means for $\mathrm{FEV}_{1}$ and PEFR are compared using a $t$ test.

For change in MMEF as percentage predicted over first three days, group medians are compared using a Mann-Whitney test, and the difference $(\mathrm{A}-\mathrm{P})$ is the point estimate for the difference between medians.

A; aminophylline, P; placebo, n; number of subjects.

was used to compare pulmonary function tests between groups after adjusting for baseline. A change in ASS from baseline at six hours was the principal outcome for ASS, but a repeated measures analysis of variance was also used to compare treatment groups at multiple points. Differences in proportions were compared using Fisher's exact test and by calculating the odds ratio (OR) and $95 \%$ confidence intervals. A $p$ value of $<0.05$ was taken as significant. Analysis was performed using Minitab for Windows (release 10.5 Xtra, 1995, Minitab Inc, State College, Pennsylvania, USA), and Stata (version 4.0, Stata Corp, Texas, USA).

\section{Results}

Subjects were enrolled from March 1994 to November 1995. During this period there were 1300 admissions to our institution with severe acute asthma, most of whom were not eligible for the study because they were not ill enough. One hundred ninety one families were approached for consent to enter the study, of which 163 consented. Table 1 give the baseline characteristics of the 163 study subjects. The trial profile is shown in fig 1 .

For the aminophylline group, 79 subjects had a first level (post-loading dose) and $42 \mathrm{had}$ a second level (after 12-18 hours of receiving continuous infusion). The first theophylline concentration was $<55 \mu \mathrm{mol} / 1$ in four subjects (5\%), 55-79 in $26(33 \%), 80-110$ in $42(53 \%)$, and $>110$ in seven (9\%). For the second level, the numbers of subjects were three $(7 \%), 15$ (35\%), $11(26 \%)$, and $13(31 \%)$, respectively.

The geometric mean length of stay for the placebo group was 2.87 days and for the aminophylline group 2.69 days. The ratio aminophylline length of stay to placebo length of stay was 0.94 (95\% confidence interval (CI) 0.77 to $1.14, \mathrm{p}=0.53)$. Thus aminophylline could have reduced the length of stay by as much as $23 \%$, or increased it by as much as $14 \%$.

There were 83 subjects older than 6 years (41 aminophylline, 42 placebo), of whom 48 $(58 \%)$ were able to perform pulmonary function tests at baseline. Table 2 shows the change in pulmonary function tests at 6 , $12-18$, and 24 hours for the 42 subjects able to perform tests at both baseline and six hours. Adjustment of the mean change at six hours for baseline values using analysis of covariance made no difference to the results.

Table 1 gives the baseline $\mathrm{SaO}_{2}$ for each group. Twenty six subjects had an $\mathrm{SaO}_{2}<80 \%$ (11 placebo, 15 aminophylline). The overall median $\mathrm{SaO}_{2}$ was $88 \%$. Figure 2 shows the $\mathrm{SaO}_{2}$ over the first 48 hours, after which time the number of subjects was small. Aminophylline was associated with a significantly higher $\mathrm{SaO}_{2}$ up to 30 hours. Sixty two subjects in each group completed all five measurements.

Supplemental oxygen, other than that used to drive the nebulisers, was used at baseline in $59(73 \%)$ aminophylline subjects and 62 $(76 \%)$ placebo subjects. The duration of supplemental oxygen treatment was significantly greater in the placebo group than in the aminophylline group (median $18 v 6$ hours, $\mathrm{p}=0.015)$.

Eight subjects had missing data for their ASS at enrolment, having been intubated before randomisation. Table 1 shows the medians for the ASS at baseline for the remaining 155 subjects (78 aminophylline, 77 placebo). Of these $155,141(91 \%)$ had an ASS of 6 or greater, and $98(63 \%)$ had an ASS of 8 or 9 of a possible 9. The ASS was similar for the two groups. 


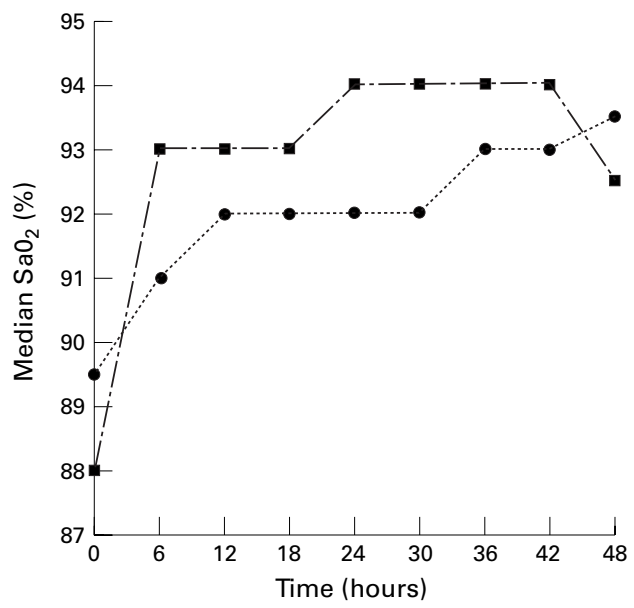

Figure 2 Median $\mathrm{SaO}_{2}$ over first 48 hours: aminophylline (squares) and placebo (circles). Differences were significant at $6,12,18,24$, and 30 hours $(p=0.004,0.01,0.004$, $0.03,0.01$, respectively).

A significant difference in the decrease in ASS occurred at six hours, favouring aminophylline (2.04 v 1.32, difference 0.72 , $95 \%$ CI 0.22 to $1.22, \mathrm{p}=0.005)$, but no significant differences existed at any other time.

Table 1 gives the baseline heart and respiratory rates. No difference occurred between groups at any time. There was no difference between groups in the geometric mean number or dose (mg) of salbutamol nebulisations given.

Seventy one subjects, $43 \%$ of the study sample, were admitted to the intensive care unit. Thirty $(42 \%)$ were in the aminophylline group and $41(58 \%)$ were in the placebo group. There was no difference in the geometric mean length of stay in the intensive care unit.

Forty one subjects, 15 in the aminophylline group and 26 in the placebo group (18 v 32\% $\mathrm{OR}=0.49,95 \%$ CI 0.23 to $0.99, \mathrm{p}=0.03)$, received intravenous salbutamol in the intensive care unit. The placebo group had a significantly longer duration (16.0 $v 8.8 \mathrm{~h}$, OR 1.82, $95 \%$ CI 1.10 to $3.25, \mathrm{p}=0.045)$ and higher total dose $(3.19 v 1.0 \mathrm{mg} / \mathrm{kg}$, OR 3.19, 95\% CI 1.35 to $7.46, \mathrm{p}=0.009$ ) of intravenous salbutamol than the aminophylline group.

Fourteen subjects underwent endotracheal intubation and mechanical ventilation, three in the aminophylline group and 11 in the placebo group. Nine of these subjects had been intubated before enrolment and randomisation (three aminophylline, six placebo), none of whom had received aminophylline before entering the study as this was an exclusion criterion. Only five subjects were intubated after randomisation and study drug administration. All five were in the placebo group $(p=0.027)$.

There was no significant difference, but there was an apparent trend to reduction in the duration of intubation between groups (aminophylline 8.25 hours, placebo 34.0 hours, $\mathrm{p}=0.087$ ) and in the median area under the curve of peak inspiratory pressure $v$ time (aminophylline $123 \mathrm{~h}-\mathrm{cmH}_{2} \mathrm{O}$, placebo 867.5 h- $\mathrm{cmH}_{2} \mathrm{O}, \mathrm{p}=0.087$ ).

Table 3 shows the number and percentage of subjects with new adverse effects (those not present at enrolment). Subjects in the aminophylline group were significantly more likely to have their infusions stopped because of adverse effects than placebo subjects (32 v 5\%, $\mathrm{OR}=8.7,95 \%$ CI 2.9 to $28.4, \mathrm{p}<0.0001)$. Two subjects had seizures during the study period, one in each group.

\section{Discussion}

The addition of aminophylline to frequent inhaled $\beta_{2}$ sympathomimetic drugs, ipratropium, and intravenous corticosteroids made no difference to the length of stay in children admitted to hospital with severe acute asthma. Aminophylline conferred clinically and statistically significant early benefits on airway function and oxygenation, sustained to 24 hours for oxygenation, but not for airway function, and reduced the risk of endotracheal intubation. At the dose used, however, it was associated with a significant risk of nausea and vomiting.

To ensure that most subjects had aminophylline concentrations above the lower limit of the therapeutic range, in contrast with some previous studies, we tried to achieve concentrations in the high part of the therapeutic range. This may explain the high incidence of side effects.

Pulmonary function tests could be performed by only half the subjects older than 6 years, the others being too ill. This was a reflection of the severity of illness in our sample, in contrast with the study of Carter et $a l,{ }^{20}$ in which ability to perform pulmonary function testing was a requirement. Other aminophylline studies in children did not document pulmonary function tests, ${ }^{1618}{ }^{19}$ apart from that of Pierson et al, ${ }^{17}$ who found an improvement of 6 and $16 \%$ at 1 and 24 hours respectively with aminophylline. The improvement in pulmonary function tests with aminophylline in this study can be compared with that seen with other drugs used in addition

Table 3 Frequency of new adverse effects in both groups after enrolment

\begin{tabular}{|c|c|c|c|c|c|c|c|c|c|}
\hline \multirow[b]{2}{*}{ Adverse effect } & \multicolumn{3}{|c|}{ Aminophylline } & \multicolumn{3}{|c|}{ Placebo } & \multicolumn{3}{|l|}{ Difference } \\
\hline & New & $\begin{array}{l}\text { Absent at } \\
\text { baseline }\end{array}$ & $\%$ & New & $\begin{array}{l}\text { Absent at } \\
\text { baseline }\end{array}$ & $\%$ & $A-P \%$ & $95 \% C I$ & $p$ value * \\
\hline Nausea & 29 & 44 & 66 & 7 & 31 & 23 & 43 & (23 to 64 ) & 0.0004 \\
\hline Vomiting & 35 & 52 & 67 & 8 & 42 & 19 & 48 & (30 to 66 ) & 0.0001 \\
\hline Headache & 15 & 62 & 24 & 15 & 67 & 22 & 2 & ( -13 to 16$)$ & 0.84 \\
\hline Irritability & 23 & 57 & 40 & 20 & 53 & 38 & 3 & ( -16 to 21$)$ & 0.85 \\
\hline Tremor & 27 & 40 & 68 & 20 & 34 & 59 & 9 & ( -13 to 31$)$ & 0.48 \\
\hline Seizures & 1 & 80 & 1 & 1 & 82 & 1 & 0 & ( -3 to 3$)$ & 1.0 \\
\hline Any new & 11 & 11 & 100 & 4 & 7 & 57 & 43 & (6 to 80 ) & 0.04 \\
\hline
\end{tabular}

Percentages are rounded to the nearest whole number.

${ }^{\star} \mathrm{p}$ value by Fisher's exact test, two tailed.

A, aminophylline; $P$, placebo. 
to nebulised salbutamol for severe acute asthma in children. It was similar in magnitude to that for $\mathrm{FEV}_{1}$ found in a study of ipratropium bromide (10.3 $v 10.4 \%$ in the present study), ${ }^{2}$ and for peak flow in a study of prednisolone $(11.8$ v $15.1 \%){ }^{24}$

The interpretation of the $\mathrm{SaO}_{2}$ data may be limited by the 10 minute washout period, which may have been insufficient to reduce alveolar $\mathrm{PaO}_{2}$ to atmospheric levels, as evidenced by the child with an $\mathrm{SaO}_{2}$ of $100 \%$ on entry. Despite this limitation, however, the median $\mathrm{SaO}_{2}$ in the aminophylline group was significantly higher at six hours than in the placebo group $(93 \% v$ $91 \%$ ), even though the aminophylline group had started with a lower median $\mathrm{SaO}_{2}(88 v 89.5 \%)$. This difference is small, but was sustained to 30 hours. Furthermore, there was a significant difference in the median duration of supplemental oxygen treatment of $6 v 18$ hours $(p=0.015)$, favouring aminophylline. It is not possible to say whether this improvement in oxygenation with aminophylline represents an improvement in alveolar ventilation, ventilation-perfusion mismatch, or both.

At six hours there was a significantly greater improvement in ASS in the aminophylline group than in the placebo group. The mean difference in decrease in ASS at six hours was 0.72 , favouring aminophylline. There was no difference in heart rate between the two groups. We suggest that the expected decrease in heart rate with a faster recovery in the aminophylline group was masked by the pharmacological effects of the drug on the heart (tachycardia).

Five subjects in the placebo group, $7 \%$, compared with none in the aminophylline group $(p=0.027)$ were intubated and mechanically ventilated. This may have important implications for clinical practice.

The sample (163 subjects) was the largest of any published study of aminophylline in children with severe acute asthma and was sufficient to exclude a reduction in length of stay in hospital by more than $23 \%$ or an increase by more than $14 \%$.

We aimed to study the effect of aminophylline in addition to maximum treatment with other drugs: frequent nebulised salbutamol, systemic corticosteroids, and nebulised ipratropium. We used ipratropium every four to six hours, as was the usual practice at our institution. Ipratropium given every 20 minutes has, however, been shown to be superior to less frequent doses. ${ }^{2}$ Ideally, the study should be repeated using frequent ipratropium as well as frequent salbutamol.

The study raises questions for further research. The finding that aminophylline reduced the risk of intubation and mechanical ventilation requires confirmation. It would be best to study a population with a higher prior probability of intubation, such as those with a history of previous intubation admitted to an intensive care unit with severe acute asthma, ${ }^{25}$ because this group stands to benefit most from such an effect.

The role of aminophylline in children already mechanically ventilated has not been addressed adequately by this study because the number of subjects involved (14) was small and the methods of measurement not ideal. Future research in this area would include more accurate measurements of respiratory mechanics, such as compliance and resistance. Future research into the role of aminophylline should include a comparison with salbutamol given intravenously.

In conclusion, in children with severe acute asthma unresponsive to maximum treatment with $\beta_{2}$ sympathomimetic drugs and systemic corticosteroids, aminophylline confers an additional early benefit on airway function and a more sustained benefit on oxygenation, but at the cost of a high frequency of adverse effects. The improvement in airway function is comparable in magnitude with that produced by corticosteroids and frequent ipratropium. Aminophylline reduces the risk of endotracheal intubation and mechanical ventilation.

On the basis of these findings, the clinician faced with an ill child with severe acute asthma unresponsive to salbutamol and corticosteroids should use treatments with a lower risk of adverse effects, such as frequent ipratropium, in preference to aminophylline, but aminophylline should maintain its place as an emergency treatment for severe acute asthma in critically ill children when other treatments have been unsuccessful.

Michael Yung was supported by a Trainee Research Fellowship from the Royal Children's Hospital Research Foundation. John Carlin provided statistical advice.

1 Phelan P, Olinsky A, Robertson C. Asthma: clinical patterns and management. In: Respiratory illness in children. 4 th edn. Oxford: Blackwell, 1994:149-83.

2 Schuh S, Johnson D, Callahan S, Canny G, Levison H. Efficacy of frequent nebulised ipratropium added to frequent high-dose albuterol therapy in severe childhood asthma. $\mathcal{F}$ Pediatr 1994;126:639-45.

3 National Heart, Lung and Blood Institute. Expert Panel Report: Guidelines for the diagnosis and treatment of asthma. Bethesda, Maryland: National Institutes for Health, 1991: 136. Publication 91-3042.

4 British Thoracic Society. Acute severe asthma in adults and children. Thorax 1993;48:S12-18.

5 Josephson G, Mackenzie E, Lietman P, Gibson G. Emergency treatment of asthma. A comparison of two Emergency treatment of asthma. A comparis
treatment regimens. $\mathscr{F} A M A$ 1979;242:639-43.

6 Rossing T, Fanta C, McFadden E. A controlled trial of single versus combined drug therapy in the treatment of acute episodes of asthma. Am Rev Respir 1981;123:190-4.

7 Fanta C, Rossing T, McFadden E. Emergency treatment of asthma: relationships among therapeutic combinations, severity of obstruction and time course of response. $A m \mathcal{F}$ Med 1982;72:416-22.

8 Self TH, Abou SN, Burns R, et al. Inhaled albuterol and oral prednisone therapy in hospitalised adult asthmatics. Does aminophylline add any benefit? Chest 1990;98:1317-21.

9 Murphy D, McDermott M, Rydman R, Sloan E, Zalenski R. Aminophylline in the treatment of acute asthma when beta2-adrenergics and steroids are provided. Arch Intern Med 1993;153:1784-8.

10 Siegal D, Sheppard D, Gelb A, Weinberg P. Aminophylline Siegal D, Sheppard D, Gelb A, Weinberg P. Aminophyline
increases the toxicity but not the efficacy of an inhaled beta-adrenergic agonist in the treatment of acute exacerbations of asthma. Am Rev Respir Dis 1985;132:283-6.

11 Coleridge J, Cameron P, Epstein J, Teichtahl H. Intravenous aminophylline confers no benefit in acute asthma treated with intravenous steroids and inhaled bronchodilators. Aust NZ F Med 1993;23:348-54.

12 Rodrigo C, Rodrigo G. Treatment of acute asthma. Lack of therapeutic benefit from aminophylline given in addition to high doses of salbutamol delivered by metered dose inhaler with a spacer. Chest 1994;106:1071-6.

13 Zainudin BM, Ismail O, Yusoff K. Effect of adding aminophylline infusion to nebulised salbutamol in severe acute asthma. Thorax 1994:49:267-9.

14 Huang D, O'Brien RG, Harman E, et al. Does aminophylline benefit adults admitted to the hospital for an acute exacerbation of asthma? Ann Intern Med 1993;119:1155-60.

15 Wrenn K, Slovis CM, Murphy F, Greenberg RS. Aminophylline therapy for acute bronchospastic disease in the emergency room. Ann Intern Med 1991;115:241-7. 
16 Needleman J, Kaifer M, Nold J, Shuster P, Redding M, Gladstein J. Theophylline does not shorten hospital stay for children admitted with asthma. Arch Pediatr Adolesc Med 1995;149:206-9.

17 Pierson W, Bierman C, Stamm S, VanArsdel P. Doubleblind trial of aminophylline in status asthmaticus. Pediatrics 1971;48:642-6.

18 DiGiulio G, Kercsmar C, Krug S, Alpert S, Marx C. Hospital treatment of asthma: lack of benefit from theophylline given in addition to nebulised albuterol and intravenously administered corticosteroid. F Pediatr 1993;122:464-9.

19 Strauss RE, Wertheim DL, Bonagura VR, Valacer DJ. Aminophylline therapy does not improve outcome and
increases adverse effects in children hospitalized with acute asthmatic exacerbations. Pediatrics 1994;93:205-10.

20 Carter E, Cruz M, Chesrown S, Shieh G, Reilly K, Hendeles L. Efficacy of intravenously administered aminophylline in children hospitalised with severe asthma. F Pediatr 1993; 122:470-6.

21 Knudson R, Lebowitz M, Holberg C, Burrows B. Changes in the normal maximal expiratory flow-volume curve with growth and aging. Am Rev Respir Dis 1983;127:725-34.

22 Bishop J, Carlin J, Nolan T. Evaluation of the properties and reliability of a clinical severity scale for acute asthma in children. F Clin Epidemiol 1992;45:71-6.

23 Dallal G. PC Size: a program for sample size determinations. American Statistician 1990;44:243.

24 Storr J, Barrell E, Barry W, Lenney W, Hatcher G. Effect of a single dose of prednisolone in acute childhood asthma. Lancet 1987;i:879-82.

25 Cox R, Barker G, Bohn D. Efficacy, results, and complications of mechanical ventilation in children with status asthmaticus. Pediatr Pulmonol 1991;11:120-6.

\section{The first randomised controlled trial}

The Dutch trials of paludrine in malaria and the MRC's first trial of streptomycin in pulmonary tuberculosis are usually cited as the first publications of the results of randomised controlled trials (RCT). They were both published in the late 1940s. They indeed are probably the first reports of RCTs with a positive outcome. However, negative trials are equally important and results of trials of patulin as a treatment for the common cold were published as a letter in $1943^{1}$ and a full paper in $1944^{2}$ by Stansfeld and colleagues. Jim Stansfeld who died in 1998 was later to become the first paediatrician in the City of Durham from 1950-82. In his self written obituary he wrote "Later posted to Bovington Camp, Dorset, in order to investigate a supposed cure for common colds-which proved useless." With this he dismissed, or did not recognise, his major contribution to medical science.

Patulin was isolated in 1941 as part of a search for antibacterial substances produced by molds. It was sent to Dr W E Gye who was investigating anticancer agents. He had a severe cold at the time and tested patulin on himself with encouraging results. Further tests on other staff members were equally positive. A supply was made available to the army in March 1943 and over the next six months 100 soldiers with severe colds were given either patulin or a placebo on an alternate basis. The subjects improved equally quickly and they concluded that patulin had no demonstrable effect on the course of the disease.

Patulin was useless, but this first randomised trial probably saved a huge number of people the indignity of a useless treatment.

1 Stuart-Harris CH, Francis AE, Stansfeld JM. Patulin in the common cold [letter]. Lancet 1943;ii: 6842 .

2 Stansfeld JM, Francis AE, Stuart-Harris CH. Laboratory and clinical trials of patulin. Lancet 1944;ii:370-6.

A W CRAFT

We encourage the submission of short pieces of historical interest to be published as fillers.

THE EDITORS 